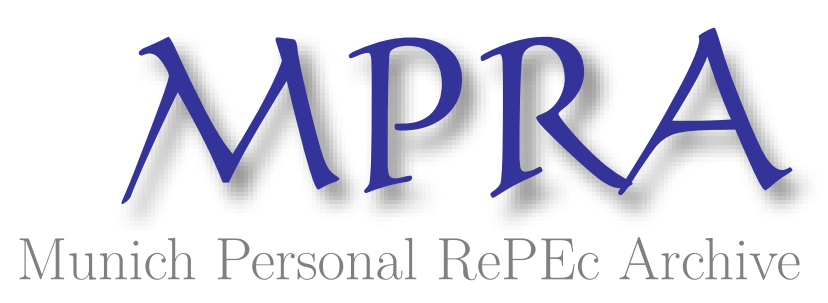

\title{
Positive self-image in tournaments
}

Santos-Pinto, Luís

Universidade Nova de Lisboa

10 November 2003

Online at https://mpra.ub.uni-muenchen.de/3140/

MPRA Paper No. 3140, posted 09 May 2007 UTC 


\title{
Positive Self-Image in Tournaments ${ }^{\dagger}$
}

\author{
Luís Santos-Pinto \\ Universidade Nova de Lisboa, Departamento de Economia \\ Campus de Campolide, PT-1099-032, Lisboa, Portugal \\ Email address: lspinto@fe.unl.pt
}

First version: November 10, 2003

This version: February 27, 2007

\begin{abstract}
This paper analyzes the implications of worker overestimation of productivity for firms in which incentives take the form of tournaments. Each worker overestimates his productivity but is aware of the bias in his opponent's self-assessment. The manager of the firm, on the other hand, correctly assesses workers' productivities and self-beliefs when setting tournament prizes. The paper shows that, under a variety of circumstances, firms make higher profits when workers have positive self-image than if workers do not. By contrast, workers' welfare declines due to their own misguided choices.
\end{abstract}

JEL Codes: A12; J41.

Keywords: Self-Image; Tournaments; Behavioral Economics.

${ }^{\dagger}$ This paper is part of my Ph.D. dissertation in University of California, San Diego. I am indebted to my advisor, Joel Sobel, for extremely helpful suggestions. I would also like to thank seminar participants at University of Montreal, Universidade Nova de Lisboa, University of California, San Diego, University of East Anglia, University of Innsbruck, and two anonymous referees for many insightful comments. I gratefully acknowledge financial support from Praxis XXI and Fundação Calouste Gulbenkian. 


\section{Introduction}

This paper is related to a recent strand of literature in economics that studies the welfare consequences of behavioral biases. The paper focuses on the welfare implications of worker overestimation of skill when firms use tournaments to provide incentives. ${ }^{1}$

The paper finds that, under a variety of circumstances, firms can benefit from worker positive self-image if they wisely structure prizes in tournaments. The paper argues that in order to do that firms should take into account how self-image changes workers' incentives to exert effort. The findings are consistent with the idea that some parties involved in a contract might gain when other parties are not fully rational.

In this paper a worker with a positive self-image overestimates his productivity of effort but has an accurate assessment of his cost of effort and his outside option. The firm correctly assesses workers' productivities and self-beliefs. Each worker is aware that his opponent's perception of ability is mistaken but thinks that his own perception is correct. Thus, the firm and each worker hold divergent beliefs about the worker's productivity. ${ }^{2}$

Positive self-image makes participation in tournaments more attractive to workers than it should actually be. Since in a tournament higher prizes are paid to workers who produce higher output, a worker who overestimates his productivity will be overly confident that he will attain a high prize. However, positive self-image might reduce effort provision. A worker who perceives that his probability of winning the tournament is very high may think that by reducing effort the decrease in disutility of effort more than compensates the decrease in utility steaming from a lower probability of success. Clearly, these two effects work in opposite directions.

The paper shows that if workers are risk averse and positive self-image reduces effort provision but not by much, then the firm's profits are higher with a positive self-image workforce than with an accurate workforce. For this to happen the firm needs to increase the prize spread (the difference between the winner's prize and the loser's prize) and reduce prizes. The intuition for this result is as follows. The firm can counter the unfavorable impact of positive self-image on effort by increasing the prize spread. Worker

\footnotetext{
${ }^{1}$ Tournaments are one of many forms of providing incentives in firms. Managers are involved in promotion tournaments: vice-presidents compete to be promoted to president and senior executives compete to become CEO. Salespeople are often paid bonuses that depend on their sales relative to those of the other salespeople in the firm.

${ }^{2}$ In the standard tournament literature all parties are assumed to hold identical and accurate beliefs regarding the distribution of output induced by workers' effort choices.
} 
risk aversion implies that workers must be compensated for the increase in the prize spread. However, worker positive self-image makes participation in the tournament more attractive to workers than it should actually be and this allows the firm to reduce prizes. If the unfavorable impact of positive self-image on effort is small, then the firm can increase the prize spread and reduce prizes.

It could also be argued that positive self-image raises effort. A worker who thinks that he is more able than others may think that if he works harder the increase in utility associated with a higher probability of success more than compensates the increase in disutility associated with higher effort. The paper shows that the firm is always better off with a positive self-image workforce when self-image raises effort. This happens because the firm can get more effort for a fixed prize structure or get the same amount of effort with lower prizes. This result is valid under very general conditions.

There could also be a non-monotonic relation between self-image and effort. For example, positive self-image may increase effort when a worker's effort level is lower than that of his coworkers but reduce it when it is higher. ${ }^{3}$ Matters are not so straightforward in this case but the paper argues, using two examples, that the results obtained before also apply here. The examples also show that the relation between self-image and effort not only depends on workers' perceptions of skill but also on technology.

Additionally, the paper shows that global welfare is lower with risk neutral workers who overestimate their productivity than with risk neutral workers who have accurate perceptions of skill. By contrast, if workers are risk averse, have moderate levels of positive self-image, and self-image and effort are complements, then global welfare is higher. This happens because overestimation of skill reduces the moral hazard problem caused by risk aversion.

Evidence from psychology and economics shows that most individuals hold overly favorable views of their skills. ${ }^{4}$ This tendency is also present in workers' self-assessments of performance in their jobs. Myers (1996) cites a study according to which: "In Australia, 86 percent of people rate their job performance as above average, 1 percent as below average." Entrepreneurs, currency traders, and fund managers have also been shown to overestimate their skills. Camerer and Lovallo (1999) provide experimental evidence that supports for the notion that tournaments attract individuals who overesti-

\footnotetext{
${ }^{3}$ As far as I know there is no study in the psychology or economic literatures that analyzes the empirical relation between self-image and effort.

${ }^{4}$ The evidence is presented in Section 7.
} 
mate their skills. The evidence has stimulated research in economics and finance.

This paper is an additional contribution to the growing literature on the impact of behavioral biases on markets and organizations. The paper is closely related to papers in that literature that study the impact of biased beliefs on the employment relationship. ${ }^{5}$

Hvide (2002) shows that a worker can gain from overestimating his skill if that improves his bargaining position against the firm (the outside option). The firm is made worse off by the worker's positive self-image. Gervais and Goldstein (2004) find that a team is better off with workers that overestimate their skill when there are complementarities between workers' efforts.

The main contribution of this paper is to show how firms can design prize structures in tournaments to take advantage of workers' inflated selfperceptions of skill. The findings in this paper stand in contrast to those in Hvide (2002) and do not rely on the assumption of complementarity between workers' efforts present in Gervais and Goldstein (2004).

The paper is structured as follows. Section 2 sets-up the model. Section 3 specializes the model. Section 4 studies the impact of self-image on the firm's welfare when workers are risk neutral. Section 5 considers the case of worker risk aversion. Section 6 looks at workers' welfare. Section 7 consider global welfare. Section 8 presents evidence on positive self-image and discusses implications and assumptions of the model.

\section{Set-up}

This section incorporates worker positive self-image into a general rankorder tournament model. The timing of the model is as follows: (1) the firm chooses the optimal prizes; (2) workers observe the realization of a common "environmental" shock (this may be interpreted as an uncertain factor specific to one activity but that affects all workers within that activity similarly); (3) workers choose simultaneously the optimal level of effort after observing the realization of the common shock and the prizes chosen by the firm; (4) the output of each worker is determined by the worker's effort choice, the common shock, and an idiosyncratic shock specific to each agent and distributed independently across agents; (5) the firm observes the workers' ranking in terms of output; and (6) the firm awards the prizes to

\footnotetext{
${ }^{5}$ I will focus on papers that use the principal-agent with unobservable effort approach to model the worker-firm relationship. Ando (2004) studies the implications of overestimation of skill in contests where workers' efforts are assumed to be observable by the firm.
} 
the workers according to their ranking. ${ }^{6}$

Throughout the paper attention is restricted to tournaments played between two workers. ${ }^{7}$ Let $U^{i}\left(y^{i}, a^{i}\right)$ denote worker $i$ 's von NeumannMorgenstern utility function, which is assumed to be increasing in income, $y^{i}$ and decreasing in effort, $a^{i}$, with $a^{i} \in \mathcal{A}^{i}=[0, \infty), i=1,2$. Let $\bar{U}$ represent the utility of an outside option. Worker $i$ 's output, $q^{i}$, is a stochastic function of his effort, in the sense that each level of effort induces a distribution over output

$$
G^{i}\left(q^{i} \mid e^{i}\left(a^{i}, \omega\right)\right)
$$

$i=1,2$, where $e^{i}\left(a^{i}, \omega\right)$ is a measure of worker $i$ 's productivity and $\omega$ is the common shock. A worker's productivity is assumed to strictly increasing in effort but marginal productivity is subject to diminishing returns to effort. The cumulative distribution $G^{i}\left(q^{i} \mid e^{i}\right)$ is assumed to satisfy the monotone likelihood ratio condition, that is, for $q_{2}^{i}>q_{1}^{i}$ and $e_{2}^{i}>e_{1}^{i}$

$$
\frac{g^{i}\left(q_{2}^{i} \mid e_{2}^{i}\right)}{g^{i}\left(q_{2}^{i} \mid e_{1}^{i}\right)}>\frac{g^{i}\left(q_{1}^{i} \mid e_{2}^{i}\right)}{g^{i}\left(q_{1}^{i} \mid e_{1}^{i}\right)},
$$

$i=1,2$, where $g^{i}\left(q^{i} \mid e^{i}\right)$ is the density function of $G^{i}\left(q^{i} \mid e^{i}\right) .{ }^{8}$ Worker $i$ 's perception of his productivity is given by $e^{i}\left(a^{i}, \lambda^{i}, \omega\right)$, where $\lambda^{i} \in \mathbf{R}^{+}$parameterizes worker $i$ 's degree of positive self-image. So, from worker $i$ 's perspective, each level of effort induces a distribution over output

$$
G^{i}\left(q^{i} \mid e^{i}\left(a^{i}, \lambda^{i}, \omega\right)\right)
$$

$i=1,2$. Worker $i$ has a positive self-image if $G^{i}\left(q^{i} \mid e^{i}\left(a^{i}, \lambda^{i}, \omega\right)\right)$ first-order stochastically dominates $G^{i}\left(q^{i} \mid e^{i}\left(a^{i}, \omega\right)\right)$ for all $a^{i} \in \mathcal{A}^{i}$. That is, for any effort level of worker $i$, worker $i$ thinks that he is more likely to produce higher levels of output than he actually is. When $G^{i}\left(q^{i} \mid e^{i}\left(a^{i}, \lambda^{i}, \omega\right)\right) \equiv$ $G^{i}\left(q^{i} \mid e^{i}\left(a^{i}, \omega\right)\right)$ we say that worker $i$ has an accurate self-image and let $\lambda^{i}=\gamma^{i}$.

\footnotetext{
${ }^{6}$ By assumption, in a tournament, the managers of the firm are not able to observe workers' effort choices. This introduces the element of moral hazard to this multi-agent setting. The firm is also not able to observe the realization of the common shock and the realization of the idiosyncratic shocks.

${ }^{7}$ This symplifies the algebra. The results in this paper generalize to tournaments with more than two workers.

${ }^{8}$ It is a well known result that this condition implies that $F^{i}\left(q^{i} \mid e_{2}^{i}\right)$ first-order stochastically dominates $F^{i}\left(q^{i} \mid e_{1}^{i}\right)$, for $e_{2}^{i}>e_{1}^{i}$.
} 
Worker $i$ 's mistaken beliefs of productivity influence behavior through worker $i$ 's perceived probability of winning the tournament. For a given output level of worker $j$, say $\bar{q}^{j}$, worker $i$ perceived probability of winning the tournament is given by

$$
\begin{aligned}
\operatorname{Pr}\left(Q^{i} \geq q^{j}\right) & =1-\operatorname{Pr}\left(Q^{i} \leq q^{j}\right) \\
& =1-G^{i}\left(q^{j} \mid e^{i}\right) .
\end{aligned}
$$

Thus, worker $i$ 's (unconditional) perceived probability of winning the tournament is given by

$$
P^{i}\left(a^{i}, a^{j}, \lambda^{i}\right)=\int\left[1-G^{i}\left(q^{j} \mid e^{i}\left(a^{i}, \lambda^{i}, \omega\right)\right)\right] g^{j}\left(q^{j} \mid e^{j}\left(a^{j}, \omega\right)\right) d q^{j},
$$

$j \neq i, i=1,2$. We see that (1), (2), (3), and (4) imply that worker $i$ 's perceived probability of winning the tournament is increasing in worker $i$ 's effort choice, decreasing in worker $j$ 's effort choice, and increasing worker $i$ 's self-image. Furthermore, if worker $i$ has a positive-self-image then

$$
P^{i}\left(a^{i}, a^{j}, \lambda^{i}\right)>P^{i}\left(a^{i}, a^{j}, \gamma^{i}\right) .
$$

To be able to compute equilibria when workers' hold mistaken beliefs the paper follows Squintani's (2006) approach and assumes that: (1) the manager of the firm correctly assesses workers' abilities and self-beliefs, (2) each worker is aware that his opponent's perception of ability is mistaken, and (3) each worker thinks that his own perception of ability is correct.

Worker $i$ 's ex post monetary income from taking part in the tournament is given by

$$
y^{i}=\left\{\begin{array}{cc}
y_{L} & \text { if } q^{i}<q^{j} \\
y_{W} & \text { otherwise }
\end{array}\right.
$$

$j \neq i, i=1,2$, where $y_{L}$ is the loser's prize and $y_{W}$ the winner's prize, with $y_{L}<y_{W}$. Worker $i$ 's interim perceived expected utility (the utility after having observed the realization of the common shock but before the realization of the idiosyncratic shocks) is given by

$V^{i}\left(a^{i}, a^{j}, \lambda^{i}, y_{L}, y_{W}\right)=U^{i}\left(y_{L}, a^{i}\right)+P^{i}\left(a^{i}, a^{j}, \lambda^{i}\right)\left[U^{i}\left(y_{W}, a^{i}\right)-U^{i}\left(y_{L}, a^{i}\right)\right]$

$j \neq i, i=1,2$, and worker $i$ 's ex ante perceived expected utility is given by

$$
E\left[V^{i}\left(a^{i}, a^{j}, \lambda^{i}, y_{L}, y_{W}\right)\right],
$$


$j \neq i, i=1,2$, where the expectation is taken with respect to the common shock.

The firm is assumed to be risk neutral and to be concerned exclusively with the maximization of profits, that is, the difference between expected benefits and compensation costs:

$$
\pi(q, y)=E\left[Q^{1}+Q^{2}\right]-\left(y_{L}+y_{W}\right) .
$$

Our analysis will focus on the monopsonistic firm, that is, a firm selling its product in a competitive output market but that has considerable influence in the input (labor) market. ${ }^{9}$ The firm's problem is to find the optimal wages for the winning and the losing parties, $\left(y_{L}, y_{W}\right)$ and the optimal effort choice for the workers, $\left(a^{1}, a^{2}\right)$, subject to the constraint that the latter be implemented as a Nash equilibrium between the workers by the chosen incentive scheme and the constraint that each worker receives an ex-ante perceived expected utility that is at least his reservation utility. Thus, the firm solves

$$
\begin{aligned}
& \max _{a^{1}, a^{2}, y_{L}, y_{W}} E\left[\sum_{i=1,2} \int q^{i} g^{i}\left(q^{i} \mid e^{i}\right) d q^{i}\right]-\left(y_{L}+y_{W}\right) \\
& \text { s.t. } \quad a^{i} \in \arg \max _{a^{i} \in \mathcal{A}^{i}} V^{i}\left(a^{i}, a^{j}, \lambda^{i}, y_{L}, y_{W}\right), i=1,2, \\
& E\left[V^{i}\left(a^{i}, a^{j}, \lambda^{i}, y_{L}, y_{W}\right)\right] \geq \bar{U}, i=1,2 .
\end{aligned}
$$

\section{The Specialized Model}

This section specializes the model and shows that an equilibrium exists. I consider a special case of Nalebuff and Stiglitz's (1983) rank-order tournament model. This is the tournament model which is closest to the standard treatment of moral hazard problems.

First, I assume that workers are weakly risk averse and have identical von Neumann-Morgenstern utility functions additively separable in income and effort, that is

$$
U^{i}\left(y^{i}, a^{i}\right)=u\left(y^{i}\right)-c\left(a^{i}\right)
$$

where $u$ and $c$ are twice differentiable with $u^{\prime}>0, u^{\prime \prime} \leq 0, c^{\prime}>0, c^{\prime \prime}>0$, and $c(0) \geq 0$. Second, I assume that workers have the same degree of positive

\footnotetext{
${ }^{9}$ This is the dual of the principal's problem in Lazear and Rosen (1981) and Nalebuff and Stiglitz (1983), where the principal maximizes the constestants' utilities while being constrained by a competitive labor market to make zero expected profits.
} 
self-image, that is $\lambda^{1}=\lambda^{2}=\lambda$. Third, I assume that there is no common shock to simplify the analysis. Fourth, worker's perceived stochastic production function is given by

$$
Q^{i}=e^{i}\left(a^{i}, \lambda\right)+\varepsilon^{i}, i=1,2 .
$$

where $G^{i}$ is the distribution function of $\varepsilon^{i}, g^{i}$ its density, with $g^{i}$ symmetric, $E\left(\varepsilon^{i}\right)=0$, and $E\left(\varepsilon^{i} \varepsilon^{j}\right)=0$ for $i \neq j$. I also assume that workers' perceived stochastic production functions are identical. Worker $i$ 's perceived probability of winning the tournament function $P\left(a^{i}, a^{j}, \lambda\right)$ is given by

$$
P\left(a^{i}, a^{j}, \lambda\right)=\int\left[1-G^{i}\left(e^{j}\left(a^{j}\right)-e^{i}\left(a^{i}, \lambda\right)+\varepsilon^{j}\right)\right] g^{j}\left(\varepsilon^{j}\right) d \varepsilon^{j}
$$

Fifth, I assume that $P\left(a^{i}, a^{j}, \lambda\right)$ is twice differentiable in $a^{i}$, and differentiable in $a^{j}$ and $\lambda$. Thus, worker $i$ 's perceived expected utility is given by

$$
V^{i}\left(a^{i}, a^{j}, \lambda^{i}, y_{L}, y_{W}\right)=u\left(y_{L}\right)+P^{i}\left(a^{i}, a^{j}, \lambda\right) \triangle u-c\left(a^{i}\right),
$$

where $\triangle u=u\left(y_{W}\right)-u\left(y_{L}\right)$. Worker $i$ maximizes his perceived expected utility by choosing an optimal effort level, taking worker $j$ 's effort level, and prizes as given. Notice that, for each effort level selected by worker $j$ worker $i$ may either choose a positive effort level or a zero effort level (shirk). Thus, worker $i$ solves

$$
\max \left\{\max _{a^{i}>0}\left[P\left(a^{i}, a^{j}, \lambda\right) \triangle u-c\left(a^{i}\right)\right], P\left(0, a^{j}, \lambda\right) \triangle u-c(0)\right\} .
$$

The global incentive compatibility condition is satisfied if both the level of positive self-image as well as the variance of the idiosyncratic shocks are not excessively high. ${ }^{10}$ If the level of positive self-image is very high, the worker may think that his probability of winning the tournament is so high that he is better off by shirking.

Assuming that the global incentive compatibility condition is satisfied we can study the relaxed optimization problem

$$
\max _{a^{i}>0} P\left(a^{i}, a^{j}, \lambda\right) \triangle u-c\left(a^{i}\right) .
$$

The first-order condition for this problem is given by

$$
P_{a^{i}}\left(a^{i}, a^{j}, \lambda\right) \triangle u=c^{\prime}\left(a^{i}\right),
$$

\footnotetext{
${ }^{10}$ When the variance of the tournament is very high luck becomes much more important than effort (or self-image) and workers prefer not exert any effort. This is a standard feature of tournament models.
} 
and the second-order condition by

$$
P_{a^{i} a^{i}}\left(a^{i}, a^{j}, \lambda\right) \triangle u-c^{\prime \prime}\left(a^{i}\right)<0 .
$$

The second-order condition can be satisfied under a variety of conditions. For example, it is satisfied when the perceived probability of winning is increasing and concave in own effort, that is, $P_{a^{i} a^{i}}<0 .{ }^{11}$ The second-order condition is also satisfied if $P_{a^{i} a^{i}}\left(a^{i}, a^{j}, \lambda\right) \triangle u<\min _{a^{i}} c^{\prime \prime}\left(a^{i}\right) .{ }^{12}$

Let $\Gamma_{e}\left(\lambda, y_{L}, y_{W}\right)$ denote the workers' simultaneous effort choice subgame.

Proposition 1 If the symmetry and differentiability assumptions hold, the global incentive compatibility condition is satisfied, and $V^{i}$ is strictly concave in $a^{i}$, then there exists a unique pure-strategy symmetric Nash equilibrium of $\Gamma_{e}\left(\lambda, y_{L}, y_{W}\right)$ with $a^{i}>0, i=1,2$.

The proof that a Nash equilibrium exists relies on the classical existence result due to Debreu (1952), Glicksberg (1952), and Fan (1952). The assumptions that the workers' expected utility is differentiable and strictly concave in own effort guarantee that there exists a unique equilibrium in pure strategies. The assumption that the global incentive compatibility condition is satisfied rules out a pure-strategy equilibrium where workers shirk. The symmetry assumptions guarantee that the equilibrium is symmetric. ${ }^{13}$

In the unique symmetric pure-strategy Nash equilibrium the first-order condition of the representative worker's optimization problem becomes

$$
P_{a^{i}}(a, a, \lambda) \triangle u=c^{\prime}(a) .
$$

Equation (6) is the analogue of Nalebuff and Stiglitz's "cornerstone equation of tournaments" but now modified to take into account the presence of worker mistaken beliefs of ability. It tells us that in equilibrium workers should increase their effort level up to the point where the perceived marginal benefit of doing so-the marginal perceived probability of winning the prize times the utility differential between winning and losing-equals its incremental cost-the marginal disutility of effort.

\footnotetext{
${ }^{11}$ This condition is satisfied if $G_{e e}^{i i}(q \mid e)>0$, that is, if there are stochastically diminishing returns to effort. See Koh (1992).

${ }^{12}$ This condition ensures that workers' expected utility function is concave in own effort by requiring that the cost function is sufficiently convex. See the discussion in Lazer and Rosen (1981, p.845, fn. 2), or Nalebuff and Stiglitz (1983).

${ }^{13}$ The symmetry assumptions allow us to simplify the firm's effort implementation problem by looking only at a single worker.
} 


\section{Risk Neutral Workers}

If workers are risk neutral, we have (up to an affine transformation) $u(y)=y$ for all $y$. In this case the firm's per worker effort implementation problem is given by

$$
\begin{aligned}
\min _{y_{L}, y_{W}} & \frac{1}{2}\left(y_{L}+y_{W}\right) \\
\text { s.t. } & P_{a^{i}}(a, a, \lambda)\left(y_{W}-y_{L}\right)=c^{\prime}(a) \\
& y_{L}+P(a, a, \lambda)\left(y_{W}-y_{L}\right)-c(a) \geq \bar{U} .
\end{aligned}
$$

In the solution to this problem the participation constraint is always binding, otherwise it would be possible to implement the same effort level at a lower cost (by reducing $y_{L}+y_{W}$ while leaving $y_{W}-y_{L}$ unchanged). Solving the incentive compatibility constraint and the participation constraint for the optimal losing and winning prizes we obtain

$$
\begin{aligned}
& y_{L}=\bar{U}+c(a)-\frac{P(a, a, \lambda)}{P_{a^{i}}(a, a, \lambda)} c^{\prime}(a), \\
& y_{W}=\bar{U}+c(a)+\frac{1-P(a, a, \lambda)}{P_{a^{i}}(a, a, \lambda)} c^{\prime}(a) .
\end{aligned}
$$

Adding up (7) and (8) and diving by $1 / 2$ we have that the per worker implementation cost is given by

$$
C(a, \lambda)=\bar{U}+c(a)-\frac{P(a, a, \lambda)-\frac{1}{2}}{P_{a^{i}}(a, a, \lambda)} c^{\prime}(a) .
$$

Let $T\left(\lambda^{1}, \lambda^{2}\right)=\left\{\pi\left(q^{1}, q^{2}, y_{L}, y_{W}\right), \Gamma_{e}\left(\lambda^{1}, \lambda^{2}, y_{L}, y_{W}\right)\right\}$ denote the tournament game when the firm's profit function is given by $\pi\left(q^{1}, q^{2}, y_{L}, y_{W}\right)$ and the workers' effort choice subgame by $\Gamma_{e}\left(\lambda^{1}, \lambda^{2}, y_{L}, y_{W}\right)$. Let $\hat{\lambda}$ denote the level positive self-image that solves

$$
[P(a, a, \lambda)-P(0, a, \lambda)] \triangle u=c(a)-c(0),
$$

where $\triangle u=c^{\prime}(a) / P_{a^{i}}(a, a, \lambda)$. We use (9) to prove our next result.

Proposition 2 If workers are risk neutral, then the firm's welfare is higher in $T(\lambda)$ than in $T(\gamma)$, with $\gamma<\lambda<\hat{\lambda}$.

This result shows that if workers are risk neutral, then the firm's cost of implementing any effort level is lower with a positive self-image workforce 
than with an accurate workforce. The intuition for this result is that workers' risk neutrality together with their positive self-image allow the firm to alter the prize spread while simultaneously reducing the total prizes. The change in the prize spread allows the firm to neutralize any impact of positive selfimage on incentives. The fact that positive self-image makes participation in the tournament seem more attractive to workers than it actually should be allows the firm to reduce the total prizes. ${ }^{14}$

\section{Risk Averse Workers}

From now on I assume that workers are risk averse. Taking the firm's control variables to be utility payments $\left(u_{L}, u_{W}\right)$, where $u_{L}=u\left(y_{L}\right)$ and $u_{W}=$ $u\left(y_{W}\right)$, rather than monetary payments $\left(y_{L}, y_{W}\right)$, the firm's implementation problem is now given by

$$
\begin{array}{ll}
\min _{v_{L}, v_{W}} & \frac{1}{2} h\left(u_{L}\right)+\frac{1}{2} h\left(u_{W}\right) \\
\text { s.t. } & P_{a^{i}}(a, a, \lambda) \triangle u=c^{\prime}(a) \\
& u_{L}+P(a, a, \lambda) \triangle u-c(a) \geq \bar{U},
\end{array}
$$

where $h=u^{-1}$. If workers are risk averse the impact of positive self-image on the firm's welfare will depend on how self-image influences workers' effort choices for fixed prizes. I will consider three different possibilities: (i) substitutability, (ii) complementarity and (iii) both.

We can see from (5) that the interaction between self-image and effort in the workers' perceived expected utility comes only through the perceived probability of winning the tournament. Differentiation of the cornerstone equation of tournaments with respect to self-image give us

$$
\frac{\partial a^{i}}{\partial \lambda}=-\frac{\partial^{2} V^{i} / \partial a^{i} \partial \lambda}{\partial^{2} V^{i} / \partial\left(a^{i}\right)^{2}}=-\frac{P_{a^{i} \lambda}\left(a^{i}, a^{j}, \lambda\right)}{P_{a^{i} a^{i}}\left(a^{i}, a^{j}, \lambda\right) \triangle u-c^{\prime \prime}} .
$$

The denominator in (10) is the second-order condition and is negative. This implies that self-image and effort are substitutes when $P_{a^{i} \lambda}<0$, that is, when a higher self-image reduces workers' perceived marginal probability

\footnotetext{
${ }^{14}$ Positive self-image may be good or bad for the firm when workers are risk neutral but are protected by a limited liability constraint $\left(y_{L} \geq L \geq 0\right)$. If higher self-image reduces effort and the limited liability contraint is binding, then positive self-image is bad for the firm. This happens because the firm needs to raise the prize spread to implement a given effort level. But, since the loser's prize cannot decrease due to limited liability, the only way for the firm to increase the prize spread is to raise the winner's prize.
} 
of winning the tournament. By contrast, if a higher self-image increases workers' perceived marginal probability of winning the tournament, $P_{a^{i} \lambda}>$ 0 , self-image and effort are complements.

\subsection{Self-Image and Effort Substitutes}

When self-image and effort are substitutes the incentive effect of positive self-image is unfavorable to the firm: for a fixed prize structure, higher self-image leads workers to exert less effort than they would exert if they had accurate self-images. Recall that the participation effect of positive selfimage is favorable to the firm. Thus, the impact of worker positive self-image on the firm's welfare depends on which effect is predominant.

Now, consider the firm's implementation problem. The firm selects prizes to induce a desired level of effort subject to the individual rationality and incentive compatibility constraints. This opens the possibility that the firm, aware of workers' positive self-image and of its unfavorable effect in effort, may be able to choose a prize structure that implements the same effort levels that the firm would like to implement if workers had accurate selfimages and do it at a smaller cost. My next result provides a condition under which the firm can do that.

Proposition 3 If workers are risk averse and $-P_{\lambda} P_{a^{i}} /(1-P)<P_{a^{i} \lambda}<0$, then the firm's welfare is higher in $T(\lambda)$ than in $T(\gamma)$, with $\gamma<\lambda<\hat{\lambda}$.

The condition that $-P_{\lambda} P_{a^{i}} /(1-P) \leq P_{a^{i} \lambda}$ implies that an increase in self-image does not raise the ratio of the perceived probability of losing the tournament to the perceived marginal probability of winning the tournament. In other words, this condition guarantees that the unfavorable incentive effect of positive self-image-which works via $P_{a^{i}}$-is small by comparison with the favorable participation effect-which works via $P$.

When workers are risk averse they dislike increases in the prize spread. This makes it costly for the firm to counter the unfavorable incentive effect of positive self-image. However, when workers are risk averse and the impact of self-image on effort is not too large, then the firm can increase effort by raising the utility prize spread while reducing prizes. ${ }^{15}$ The firm does this by reducing both the loser's and the winner's prize in a way such that the reduction in the utility of the loser's prize is larger than the reduction in

\footnotetext{
${ }^{15}$ If workers are risk averse and $P_{a^{i} \lambda}<-P_{\lambda} P_{a^{i}} /(1-P)$, then there is no way to tell if implementation cost goes up or down with positive self-image without making additional assumptions.
} 
the utility of the winner's prize. This increases workers' effort and reduces compensation costs for any degree of risk aversion.

Propositions 2 and 3 tell us that for worker positive self-image to hurt firms when effort and self-image are substitutes, then there must be a large unfavorable impact of positive self-image on effort and workers must have a high degree of risk aversion.

\subsection{Self-Image and Effort Complements}

If self-image and effort are complements, then, for a fixed prize structure, positive self-image leads workers to exert more effort than they would exert if they had accurate perceptions of skill. Furthermore, positive self-image relaxes the workers' participation constraint. This implies that the firm can implement the same actions with lower prizes or obtain more output for the same prizes. Thus, the firm's welfare is higher in a tournament where workers overestimate their abilities and self-image and effort are complements, than in a tournament with accurate workers.

Proposition 4 If workers are risk averse and $P_{a^{i} \lambda} \geq 0$, then the firm's welfare is higher in $T(\lambda)$ than in $T(\gamma)$, with $\gamma<\lambda<\hat{\lambda}$.

This result can be proved under very general conditions and does not depend on the particular assumptions of the specialized model. Appendix 2 shows that if self-image and effort levels are weak complements and there is a weak complementarity in effort choices, then the firm's welfare is higher with a positive self-image workforce than with an accurate workforce.

It is easy to find perceptions of skill and production functions that lead to a complementarity between self-image and effort. For example, if output is uniformly distributed with support on $\left[\gamma a^{i}-\sigma, \gamma a^{i}+\sigma\right]$, with $\sigma>0$, each worker perceives his own output to be uniformly distributed with support on $\left[\lambda a^{i}-\sigma, \lambda a^{i}+\sigma\right]$, with $\gamma<\lambda<\hat{\lambda}$, and the cost of effort function is sufficiently convex, then effort and self-image are complements. ${ }^{16}$

${ }^{16}$ In this case, worker $i$ 's perceived probability of winning the tournament is

$$
P^{i}\left(a^{i}, a^{j}, \lambda^{i}\right)=\left\{\begin{array}{l}
\frac{1}{2}+\frac{\lambda a^{i}-a^{j}}{2 \sigma}+\frac{\left(\lambda a^{i}-a^{j}\right)^{2}}{8 \sigma^{2}}, \text { for }-2 \sigma<\lambda a^{i}-a^{j}<0 \\
\frac{1}{2}+\frac{\lambda a^{i}-a^{j}}{2 \sigma}-\frac{\left(\lambda a^{i}-a^{j}\right)^{2}}{8 \sigma^{2}}, \text { for } 0<\lambda a^{i}-a^{j}<2 \sigma
\end{array} .\right.
$$

The cross partial of $P^{i}$ with respect to $a^{i}$ and $\lambda^{i}$ is

$$
P_{a^{i} \lambda}\left(a^{i}, a^{j}, \lambda\right)=\left\{\begin{array}{l}
\frac{1}{2 \sigma}+\frac{2 \lambda a^{i}-a^{j}}{4 \sigma^{2}}, \text { for }-2 \sigma<\lambda a^{i}-a^{j}<0 \\
\frac{1}{2 \sigma}-\frac{2 \lambda a^{i}-a^{j}}{4 \sigma^{2}}, \text { for } 0<\lambda a^{i}-a^{j}<2 \sigma
\end{array} .\right.
$$

If the cost of effort is sufficiently convex, then $P_{a^{i} \lambda}\left(a^{i}, a^{j}, \lambda\right)>0$, for all $\lambda \in(\gamma, \hat{\lambda})$. 


\subsection{Non-Monotonic Relation between Self-Image and Effort}

Effort and self-image may be substitutes over some effort levels but complements over others. This case is of interest since plausible specification of workers' perceptions of skill and technology imply a non-monotonic relation between effort and self-image.

Opening up this possibility complicates the analysis substantially and I am no longer able to state general results that link worker self-image to firm welfare. So, I specialize the model even further and assume that output is either exponentially or normally distributed. ${ }^{17}$ Appendix 3 shows that both production functions imply a non-monotonic relation between self-image and effort and contains the proofs. Here, I summarize the findings and give the intuition.

When output is exponentially distributed and a worker perceives that his own effort is relatively lower than his coworker's effort, then effort and selfimage are complements. However, if a worker perceives that his own effort is relatively higher than his coworker's effort, then effort and self-image are substitutes. I find that positive self-image is always good for the firm when output is exponentially distributed and workers are risk averse. In this case positive self-image and effort are substitutes at symmetric effort levels so the firm must raise the prize spread in order to implement the same effort level as when workers have accurate perceptions of skill. However, I show that the firm is able to do that by simultaneously decreasing both the winning and losing prizes.

When output is normally distributed and workers are risk averse, worker positive self-image is beneficial to the firm for low levels of bias. This happens because for a low level of bias, positive self-image and effort are complements at symmetric effort levels. If that is the case, then the firm is able to implement the same level of effort by lowering the prize spread and reducing prizes. When positive self-image is high it is no longer clear if the firm is better off with a positive self-image or with an accurate workforce.

These two results show that even if there is there is a non-monotonic relation between effort and self-image the firm is either better off with a positive self-image workforce or the impact of positive self-image on the firm's welfare is ambiguous. They also show that if firms want to take advantage of positive self-image in the workforce, then it is critical for firms to know whether effort and self-image are substitutes or complements at symmetric effort levels.

\footnotetext{
${ }^{17}$ These are two stochastic production functions that are commonly used in the tournament literature. See Lazear and Rosen (1981) and Nalebuff and Stiglitz (1983).
} 


\section{Workers' Welfare}

From the point of view of an outside observer who knows the worker's actual productivity, if a worker's beliefs are mistaken, then the worker's ex-ante actual expected utility will differ from his reservation utility. For example, the ex-ante actual expected utility of a risk neutral worker who overestimates his productivity is given by

$$
V\left(a, \lambda, y_{L}, y_{W}\right)=\frac{y_{L}+y_{W}}{2}-c(a)=\bar{U}-\frac{P(a, \lambda)-\frac{1}{2}}{P_{a^{i}}(a, \lambda)} c^{\prime}(a),
$$

where the second equality is obtained by replacing $y_{L}+y_{W}$ by $C(a, \lambda)$. We see that if the worker overestimates his productivity, then $P(a, \lambda)>1 / 2$, and his ex-ante actual expected utility is smaller than his reservation utility.

The example illustrates a general result, that does not require a formal proof. From the perspective of an outside observer, positive self-image workers are worse off by comparison with accurate workers since the firm will pay them less than their reservation utility. ${ }^{18}$

\section{Global Welfare}

It is a well know result in the tournament literature that if workers are risk neutral and have accurate perceptions of skill, then the firm can achieve the full information first-best effort level by setting a prize spread equal to $\triangle y^{*}(\gamma)=c^{\prime}\left(a^{*}(\gamma)\right) / P_{a^{i}}\left(a^{*}(\gamma), a^{*}(\gamma)\right)$, where $a^{*}(\gamma)$ is the solution to the effort selection problem

$$
\max _{a \geq 0} E[e(a, \omega)]-c(a) .
$$

In this paper I have shown that if workers are risk neutral and have a positive self-image, then the firm can implement effort level $a^{*}(\lambda)$ by setting a prize spread equal to $\triangle y^{*}(\lambda)=c^{\prime}\left(a^{*}(\lambda)\right) / P_{a^{i}}\left(a^{*}(\lambda), a^{*}(\lambda), \lambda\right)$, where $a^{*}(\lambda)$ is the solution to

$$
\max _{a \geq 0} E[e(a, \omega)]-C(a, \lambda)
$$

\footnotetext{
${ }^{18}$ This is consistent with a growing literature which shows-using both field data and data from controlled laboratory experiments-that individuals' mistaken perceptions of risk lead to financial losses. Examples of papers in this literature are Camerer and Lovallo (1991), Simon and Houghton (2003), Malmendier and Tate (2002), and Landier and Thesmar (2003). However, it is still not clear if individuals' mistaken perceptions of risk are caused by either positive self-image, optimism, overconfidence, failure to take into account the strategic behavior of others, or a mixture of some or all of these phenomena.
} 
with $C(a, \lambda)$ given by (9). Since $C(a, \lambda)<\bar{U}+c(a)=C(a, \gamma)$ it follows that

$a^{*}(\gamma)<a^{*}(\lambda)$ for all $\lambda \in(\gamma, \hat{\lambda})$. That is, when workers are risk neutral and have positive self-image the firm will choose an effort level that is higher than the full information first-best effort level for accurate workers. This implies that global welfare is lower when workers are risk neutral and overestimate their productivity than when workers are risk neutral and have accurate perceptions of skill.

It is also a well know result that when effort is unobservable, workers are risk averse and have accurate perceptions of skill, the firm is not able to implement the first-best effort level using a tournament. In this paper I have shown that if effort is unobservable, workers are risk averse, have positive self-image, and self-image and effort are complements, then effort will increase for a fixed prize spread. It follows that global welfare may be higher when workers are risk averse and overestimates their productivity than when workers are risk averse and have accurate perceptions of skill. This happens because moderate levels of positive self-image reduce the moral hazard problem created by risk aversion. However, large levels of positive self-image may reduce global welfare since this can lead firms to select an effort level greater than the first-best effort level or make shirking overly attractive to workers.

\section{Evidence, Implications and Discussion}

This section reviews evidence from psychology and from economics for positive self-image. It also discusses the implications and main assumptions of the model.

\subsection{Evidence on the Assumptions of the Model}

Positive self-image is a staple finding in psychology. According to Myers (1996), a textbook in social psychology, “(..) on nearly any dimension that is both subjective and socially desirable, most people see themselves as better than average."

This tendency is also present in workers' self-assessments of performance in their jobs. Myers (1996) cites a study according to which: "In Australia, 86 percent of people rate their job performance as above average, 1 percent as below average." Baker et al. (1998) cite a survey of General Electric Company employees according to which: "58 percent of a sample of whitecollar clerical and technical workers rated their own performance as falling 
within the top 10 percent of their peers in similar jobs, 81 percent rated themselves as falling in the top 20 percent. Only about 1 percent rated themselves below the median." 19

Oberlechner and Osler (2004) find that 75 percent of currency traders in foreign exchange markets think they are better than average. Similarly, Brozynski et al. (2003) find that fund managers' hold overly positive views of their relative performance. ${ }^{20}$

Two studies provide direct support for the notion that tournaments attract individuals who overestimate their skills. Camerer and Lovallo (1999) consider a market entry game where subjects payoffs are based on rank, which is determined either randomly or through a test of skill. They find that there is more entry when relative skill determines payoffs, which suggests that individuals overestimated their ability to do well on the test relative to others. Park and Santos-Pinto (2005) show that players in real world poker and chess tournaments overestimate their performance and are willing to bet on their overly positive perceptions of skill.

\subsection{Implications of the Model}

The main implication of this paper for hiring decision by firms is that, everything else equal, firms should have a preference for hiring workers who overestimate skill when they use tournaments to provide incentives. In other words, if two job applicants have the same productivities, the same preferences towards risk, the same cost of effort, and the same outside option, then the firm should hire the one who holds the most positive view of his skill.

In settings where performance depends on ability positive self-image leads individuals to overestimate the probability of favorable outcomes. If this is the case individuals should, on average, prefer incentive schemes featuring payments contingent on relative performance (e.g., rank-order tournaments or incentive schemes composed partly by fixed pay and partly by variable pay dependent on the magnitude of relative performance) to individualistic incentive schemes (e.g., fixed salary plans or piece rates).

\footnotetext{
${ }^{19}$ In another study based on the same survey conducted on managerial and professional employees it was found that " 47 percent rated their performance in the top 5 percent, 83 percent rated their performance in the top $10 \%$, no one rated their performance below the 75th percentile."

${ }^{20}$ Overconfidence and positive self-image can persist and survive in the long run in financial markets-see Kyle and Wang (1997). Theoretical models of financial markets also predict that these biases lead to increased trading activity. Deaves et al. (2003) confirm this prediction using an asset market experiment.
} 


\subsection{Discussion}

In this paper the firm is a monopsonist in the market for workers' services. This assumption implies that the firm can make a take-it-or-leave it offer to the workers and get all the surplus from the employment relationship. I have made this assumption because this is the conventional approach to moral hazard problems. This assumption is appropriate when there is a large pool of workers and a small number of firms.

If there is a large number of firms competing for the services of a few workers (e.g., competition for very talented workers), then it would be more appropriate to use the dual approach to this paper. Under that approach the firm chooses tournament prizes to maximize workers' expected utility under a zero expected profit constraint. The zero expected profit constraint implies that each worker gets all the surplus from the employment relationship and so there is no impact of mistaken beliefs on the firm's welfare.

The impact of worker overestimation of skill on worker welfare when firms compete for workers' services depends on worker preferences towards risk. If workers are risk neutral and have accurate perceptions of productivity, the tournament elicits the first-best effort level. However, if workers are risk neutral and overestimate their skills the tournament no longer implements the first-best effort level and workers are worse off. When workers are risk averse the impact of positive self-image on worker's welfare is ambiguous. ${ }^{21}$

The paper studies tournaments with two workers and two prizes to make the analysis simpler. However, the results obtained extend to tournaments with more than two workers and more than two prizes. Another assumption of the paper is that the firm faces an homogeneous workforce in terms of productivity and perceptions of productivity. That is, all workers have identical productivity and all workers either overestimate, underestimate, or have accurate perceptions of productivity. If one of these two assumptions is dropped the tournament becomes asymmetric and the analysis becomes more complicated but the main findings of the paper will hold. These are simplifying assumptions that allows us to focus on the implications of workers' mistaken beliefs on the firm's welfare. ${ }^{22}$

\footnotetext{
${ }^{21}$ See De la Rosa (2005).

${ }^{22}$ Workers are likely to differ in their productivities and their perceptions of skill. Some are more skilled than others, some hold positive views of their skill while others hold negative views. If there is no correlation between skill and perceptions of skill, the results in the paper apply to the average worker in the firm.
} 


\section{Appendix 1}

Proof of Proposition 1 To show that a pure-strategy equilibrium exists I need to show that (a) worker $i$ 's strategy set is nonempty, convex, and a compact subset of $\mathbf{R}$; and (b) worker $i$ 's expected utility is continuous in $a^{i}$ and $a^{j}$, and quasiconcave in $a^{i}$. Let us start by verifying (a). Worker $i$ 's effort belong to the set $[0, \infty)$ which is not compact. However, for $a^{i}$ too large costs must dominate benefits, so these strategies are dominated. This follows from the assumption that costs are convex. So, in effect, worker $i$ 's effort will belong to a set $\left[0, \bar{a}^{i}\right]$, with $\bar{a}^{i}$ finite, which is a nonempty, convex and a compact subset of $\mathbf{R}$. Let us now verify (b). The assumptions that $u, c$ and $P$ are twice differentiable imply that worker $i$ 's perceived expected utility function is continuous in $a^{i}$ and $a^{j}$ in the set $\left[0, \bar{a}^{i}\right]$. The assumption of strictly concave of expected utility in $a^{i}$ for all $a^{i} \in\left[0, \bar{a}^{i}\right]$ implies quasiconcave of expected utility in $a^{i} \in\left[0, \bar{a}^{i}\right]$. Thus, since all the required conditions are satisfied there exists a pure-strategy Nash equilibrium. $^{23}$ The strict concavity of the expected utility function implies that the pure-strategy equilibrium is unique. The assumption that the global incentive compatibility condition is satisfied rules out a pure-strategy equilibrium with zero effort. Finally, the equilibrium is symmetric. Suppose, by contradiction, there exists an asymmetric pure-strategy Nash equilibrium such that $a^{1}>a^{2}$. Then, by the workers' first-order conditions, we have

$$
P_{a^{1}}\left(a^{1}, a^{2}, \lambda\right)\left[u\left(y_{W}\right)-u\left(y_{L}\right)\right]=c^{\prime}\left(a^{1}\right),
$$

and

$$
P_{a^{2}}\left(a^{2}, a^{1}, \lambda\right)\left[u\left(y_{W}\right)-u\left(y_{L}\right)\right]=c^{\prime}\left(a^{2}\right),
$$

with

$$
P_{a^{i}}\left(a^{i}, a^{j}, \lambda\right)=-e_{a^{i}}^{i}\left(a^{i}, \lambda\right) \int g^{i}\left(e^{j}\left(a^{j}\right)-e^{i}\left(a^{i}, \lambda\right)+\varepsilon^{j}\right) g^{j}\left(\varepsilon^{j}\right) d \varepsilon^{j},
$$

$j \neq i=1,2$. The assumption that the marginal productivity of effort is subject to diminishing returns to effort implies that

$$
e_{a^{1}}^{1}\left(a^{1}, \lambda\right)<e_{a^{2}}^{2}\left(a^{2}, \lambda\right) \text { for } a^{1}>a^{2} .
$$

\footnotetext{
${ }^{23}$ The assumption that $P$ is differentiable in $a^{i}$ and $a^{j}$ implies that $P$ is continuous in $a^{i}$ and $a^{j}$. It is a well know result that continuity of $P$ rules out situations where the variance of the idiosyncratic shocks is so small that there is no equilibrium in pure-strategies (but there is an equilibrium in mixed-strategies). See discussion in Nalebuff and Stiglitz (1983).
} 
The assumption that $G^{i}\left(q^{i} \mid e^{i}\right)$ satisfies the monotone likelihood ratio property and the symmetry assumptions imply that

$$
g^{1}\left(e^{2}\left(a^{2}\right)-e^{1}\left(a^{1}, \lambda\right)+\varepsilon^{2}\right)<g^{2}\left(e^{1}\left(a^{1}\right)-e^{2}\left(a^{2}, \lambda\right)+\varepsilon^{1}\right) \text { for } a^{1}>a^{2} .
$$

It follows from (13) and (14) that

$$
P_{a^{1}}\left(a^{1}, a^{2}, \lambda\right)<P_{a^{2}}\left(a^{2}, a^{1}, \lambda\right) .
$$

Dividing (11) by (12) and making use of (15) we obtain $c^{\prime}\left(a^{1}\right)<c^{\prime}\left(a^{2}\right)$, which contradicts $a^{1}>a^{2}$. The case $a^{1}<a^{2}$ is similar.

Proof of Proposition 2 Let $a$ denote an arbitrary effort level that the firm can implement when workers are risk neutral and have accurate self-images. If workers are risk neutral and have beliefs of productivity given by $\lambda$ and the firm selects a prize spread equal to $\Delta y=c^{\prime}(a) / P_{a^{i}}(a, \lambda)$, then the firm can implement effort level $a$. If workers have accurate self-images the symmetry of the specialized tournament model implies that $P(a, \gamma)=1 / 2$ and the last term on the right hand side of (9) is zero. In this case implementation cost is equal to $C(a, \gamma)=\bar{U}+c(a)$. If workers have positive self-image $P(a, \lambda)>1 / 2$ and the last term on the right hand side of (9) is negative. Thus, $C(a, \lambda)<C(a, \gamma)$, for all $\lambda \in(\gamma, \hat{\lambda})$.

Q.E.D.

Proof of Proposition 3 Let $a$ denote an arbitrary effort level that the firm can implement when workers are risk averse and have accurate self-images. If workers are risk averse and have a degree of positive self-image given by $\lambda$ and the firm selects a utility prize spread equal to $\triangle u(\lambda)=c^{\prime}(a) / P_{a^{i}}(a, \lambda)$ then the firm can implement effort level $a$. I will now prove that the firm can lower implementation cost. Solving the incentive compatibility constraint and the participation constraint for the utility of the losing and winning prizes we obtain

$$
\begin{aligned}
& u_{L}(\lambda)=\bar{U}+c(a)-\frac{P(a, \lambda)}{P_{a^{i}}(a, \lambda)} c^{\prime}(a), \\
& u_{W}(\lambda)=\bar{U}+c(a)+\frac{1-P(a, \lambda)}{P_{a^{i}}(a, \lambda)} c^{\prime}(a) .
\end{aligned}
$$

Implementation cost is given by

$$
C(a, \lambda)=\frac{1}{2} h\left(u_{L}(\lambda)\right)+\frac{1}{2} h\left(u_{W}(\lambda)\right) .
$$


The fact that $P$ is increasing with $\lambda$ and the assumption that $P_{a^{i} \lambda}<0$ imply that the utility of the loser's prize is decreasing with $\lambda$. The assumption that $-P_{\lambda} P_{a^{i}} /(1-P) \leq P_{a^{i} \lambda}$ implies that $(1-P) / P_{a^{i}}$ is nonincreasing with $\lambda$. This in turn implies that the utility of the winner's prize is nonincreasing with $\lambda$. If the utility of loser's prize decreases with $\lambda$ and the utility of the winner's prize is nonincreasing with $\lambda$, then implementation cost decreases with $\lambda$ as long as $-P_{\lambda} P_{a^{i}} /(1-P) \leq P_{a^{i} \lambda}<0$. This implies that $C(a, \lambda)<C(a, \gamma)$ for all $\lambda \in(\gamma, \hat{\lambda})$.

Q.E.D.

Proof of Proposition 4 Let $a$ denote an arbitrary effort level that the firm can implement when workers are risk averse and have accurate selfimages. If workers are risk averse and have a degree of positive self-image given by $\lambda$ and the firm selects a utility prize spread equal to $\triangle u(\lambda)=$ $c^{\prime}(a) / P_{a^{i}}(a, a, \lambda)$ then the firm can implement effort level $a$. If $P_{a^{i} \lambda}=0$ then positive self-image has no impact on the incentive compatibility constraint and there is no need to alter the prize spread. If $P_{a^{i} \lambda}>0$ it follows that $\triangle u(\lambda)<\triangle u(\gamma)$ for all $\lambda \in(\gamma, \hat{\lambda})$. If the prize spread decreases workers face less risk. Furthermore, positive self-image relaxes the workers' participation constraint. This implies that when $P_{a^{i} \lambda} \geq 0$ the firm can implement the same effort with lower prizes for all $\lambda \in(\gamma, \hat{\lambda})$.

Q.E.D. 


\section{Appendix 2}

This appendix shows that if there is a weak complementarity in workers' effort choices and if workers' self-image and effort levels are complements, then the firm's welfare is higher with a positive self-image workforce than with an accurate workforce.

To prove this result I need to provide conditions under which a worker's effort is increasing or decreasing with changes in positive self-image for fixed prizes. Worker $i$ 's effort choice problem, for a given realization of the common shock, is given by

$$
\max _{a^{i} \in \mathcal{A}^{i}} U^{i}\left(y_{L}, a^{i}\right)+P^{i}\left(a^{i}, a^{j}, \lambda^{i}\right)\left[U^{i}\left(y_{W}, a^{i}\right)-U^{i}\left(y_{L}, a^{i}\right)\right] .
$$

Let

$$
A^{i}\left(\lambda^{i}, y_{L}, y_{W}\right) \equiv \arg \max _{a^{i} \in \mathcal{A}^{i}} V^{i}\left(a^{i}, a^{j}, \lambda^{i}, y_{L}, y_{W}\right)
$$

denote the set of maximizers in problem (18) as a function of $\lambda^{i}, y_{L}$, and $y_{W}$. For fixed prizes, the worker will never want to choose an infinite effort. So, the worker's effort choice set is compact. We also assume that $V^{i}$ is order upper semi-continuous in $a^{i}$. This assumption together with the fact that the worker's effort choice set is compact guarantees that the set of maximizers $A^{i}\left(\lambda^{i}, y_{L}, y_{W}\right)$ is nonempty.

To make operational the view that higher self-image increases workers' effort I use the definition of increasing differences. This definition tells us that a function $h: \mathbf{R}_{+}^{\mathbf{2}} \rightarrow \mathbf{R}$ has increasing differences in $(x, \theta)$ if for all $x^{\prime \prime}>$ $x^{\prime}$, the difference $h\left(x^{\prime \prime}, \theta\right)-h\left(x^{\prime}, \theta\right)$ is nondecreasing in $\theta$. The property of increasing differences represents the economic notion of complementarity. ${ }^{24}$ Athey, Milgrom, and Roberts (1996) show that the set of maximizers defined by

$$
X(\theta ; z) \equiv \arg \max _{x \in S} h(x, \theta)+z(x),
$$

is nondecreasing in $\theta$ for all functions $z$, that is,

$$
\theta>\theta^{\prime} \text { implies } X(\theta ; z) \succsim_{S} X^{*}\left(\theta^{\prime} ; z\right)
$$

\footnotetext{
${ }^{24}$ If $h$ is a benefit function and $x^{\prime \prime}>x^{\prime}$, then the incremental benefit of increasing $x^{\prime}$ to $x^{\prime \prime}$ is $h\left(x^{\prime \prime}, \theta\right)-h\left(x^{\prime}, \theta\right)$. If $h$ has increasing differences in $(x, \theta)$, then the incremental benefit from increasing $x^{\prime}$ to $x^{\prime \prime}$ when $\theta=\theta^{\prime \prime}$ is higher than the incremental benefit from increasing $x^{\prime}$ to $x^{\prime \prime}$ when $\theta=\theta^{\prime}$, for any $\theta^{\prime \prime}>\theta^{\prime}$.
} 
if and only if the function $h: \mathbf{R}_{+}^{\mathbf{2}} \rightarrow \mathbf{R}$ has increasing differences in $(x, \theta) .^{25}$ This equivalence is used to state my first result. Define

$$
H^{i}\left(a^{i}, a^{j}, \lambda^{i}, y_{L}, y_{W}\right) \equiv P^{i}\left(a^{i}, a^{j}, \lambda^{i}\right)\left[U^{i}\left(y_{W}, a^{i}\right)-U^{i}\left(y_{L}, a^{i}\right)\right] .
$$

Lemma $1 A^{i}\left(\lambda^{i}, y_{L}, y_{W}\right)$ is nondecreasing in $\lambda^{i}$ if and only if $H^{i}$ has increasing differences in $\left(a^{i}, \lambda^{i}\right)$.

Proof An application of Theorem 2.3 in Athey et al. (1996) Q.E.D.

Lemma 1 states that if a worker's self-image and effort are complements, then the higher is self-image the higher is a worker's set of optimal effort choices. When self-image and effort are complements an increase in selfimage leads to an increase in effort since the increase in the perceived incremental probability of winning the tournament times the utility prize spread is higher when self-image is higher.

We are interested in finding necessary and sufficient conditions on the structure of the effort choice subgame that together with the conditions found on the workers' individual effort choice problems, allow us to know how the set of pure-strategy Nash equilibria effort levels changes with positive self-image.

Milgrom and Roberts (1990) show that if the game $\Gamma$ is a supermodular game then it has a pure-strategy Nash equilibrium. Furthermore, they show that $\Gamma$ is a supermodular game where the payoff functions are parameterized by $\tau$ then it is possible to provide comparative static results that link a change in $\tau$ with a change in the smallest and largest of Nash equilibrium of $\Gamma$. I make use of these results to prove existence of equilibrium in the workers' effort choice subgame and to state comparative static results relating the workers' degree of positive self-image to the smallest and the largest Nash equilibrium of the effort choice subgame.

Let $\Gamma_{e}\left(\lambda^{1}, \lambda^{2}, y_{L}, y_{W}\right)=\left\{\{1,2\},\left(\mathcal{A}^{i}, V^{i}, i \in\{1,2\}\right), \geq\right\}$ denote the simultaneous effort choice subgame for levels of positive self-image $\left(\lambda^{1}, \lambda^{2}\right)$ and for prize structure $\left(y_{L}, y_{W}\right)$. According to Milgrom and Roberts (1990), $\Gamma_{e}$ is a supermodular subgame if (i) $\mathcal{A}^{i}$ is a compact interval in $\mathbf{R}$, (ii) $V^{i}\left(a^{i}, a^{j}\right)$ is order upper semi-continuous in $a^{i}$ for fixed $a^{j}$ and order continuous in $a^{j}$ for fixed $a^{i}$, and $V^{i}\left(a^{i}, a^{j}\right)$ has a finite upper bound, (iii) $V^{i}$

\footnotetext{
${ }^{25}$ The symbol $\succsim_{S}$ stands for the strong set order. A set $M \subseteq \mathbf{R}$ is as high as another set $N \subseteq \mathbf{R}$ (in the strong set order), written $M \succsim_{S} N$, if for every $x \in M$ and $y \in N, y \geq x$ implies both $x \in M \cap N$ and $y \in M \cap N$. A set $M$ is higher than $N$, written $M \succ_{S} N$ if $M$ is as high as $N$ but $N$ is not as high as $M$. A set-valued function $V: \mathbf{R} \rightarrow \mathbf{2}^{\mathbf{R}}$ is nondecreasing if for $x>y, V(x) \succsim_{S} V(y)$.
} 
has increasing differences in $a^{i}$, and (iv) $V^{i}$ has increasing differences in $\left(a^{i}, a^{j}\right)$.

We see that $\Gamma_{e}$ satisfies condition (i) since, for any finite prize structure it is never optimal for the workers to choose an infinite amount of effort. $\Gamma_{e}$ also satisfies the first requirement of condition (ii) since we have assumed before that $V^{i}$ is order upper semi-continuous in $a^{i}, i=1,2$. Condition (iii) is satisfied trivially since workers' choice variables are scalars. So, for $\Gamma_{e}$ to be a supermodular subgame we need to assume that it also satisfies condition (iv) and the second and third requirements in condition (ii). The next result guarantees the existence of a pure-strategy Nash equilibrium in $\Gamma_{e}$ by imposing the remaining conditions that make it a supermodular subgame.

Lemma 2 If $H^{i}$ has increasing differences in $\left(a^{i}, a^{j}\right), j \neq i, i=1,2, V^{i}$ is order continuous in $a^{j}$ for fixed $a^{i}, j \neq i, i=1,2$, and $V^{i}$ has a finite upper bound, then $\Gamma_{e}\left(\lambda^{1}, \lambda^{2}, y_{L}, y_{W}\right)$ has a pure-strategy Nash equilibrium.

Proof The assumption that $H^{i}$ has increasing differences in $\left(a^{i}, a^{j}\right), j$ $\neq i, i=1,2$, implies that $V^{i}$ has increasing differences in $\left(a^{i}, a^{j}\right), j \neq i$, $i=1,2$, since the interaction between $a^{1}$ and $a^{2}$ in the workers' interim perceived payoff functions is only through $H^{i}$. The assumption that $V^{i}$ is continuous in $a^{j}$ and has a finite upper bound together with the fact that $V^{i}$ has increasing differences in $\left(a^{i}, a^{j}\right), j \neq i, i=1,2$, imply that all the conditions required for $\Gamma_{e}\left(\lambda^{1}, \lambda^{2}\right)$ to be a supermodular game are satisfied. But then, by Theorem 5 in Milgrom and Roberts (1990), $\Gamma_{e}\left(\lambda^{1}, \lambda^{2}\right)$ has a pure-strategy Nash equilibrium. Q.E.D.

The assumption that $H^{i}$ has increasing differences in $\left(a^{i}, a^{j}\right), j \neq i$, $i=1,2$, imposes the missing structure in the $\Gamma_{e}$ that, together with the two other assumptions, allows us to use the order-theoretic approach to state this existence result. This assumption restricts the type of interaction between the workers choice variables by forcing $a^{1}$ and $a^{2}$ to be weak complements. That is, we restrict attention to effort choice subgames where a worker's increase in effort makes it more desirable for his opponent to increase effort too.

The assumptions that guarantee that condition (ii) is verified rule out the possibility that there is no equilibrium and the possibility that there exists a mixed-strategy equilibrium but not a pure-strategy equilibrium. For example, if the variability of the idiosyncratic shocks is too small (chance is not a significant factor in the outcome of the tournament) the game $\Gamma_{e}$ does not satisfy condition (ii) and there is no pure-strategy equilibrium but 
there exists a mixed strategy equilibrium. ${ }^{26}$

Lemma 3 If $\Gamma_{e}\left(\lambda^{1}, \lambda^{2}, y_{L}, y_{W}\right)$ is a supermodular subgame and $H^{i}$ has increasing differences in $\left(a^{i}, \lambda^{i}\right), i=1,2$, then the smallest and the largest pure-strategy Nash equilibria of $\Gamma_{e}\left(\lambda^{1}, \lambda^{2}, y_{L}, y_{W}\right)$ are nondecreasing functions of $\left(\lambda^{1}, \lambda^{2}\right)$.

Proof An application of Theorem 6 in Milgrom and Roberts (1990). Q.E.D.

Lemma 3 states that if there is a weak complementarity in the workers' effort choices and if workers' self-image and effort levels are complements, then the higher is the workers' degree of positive self-image the higher will be the smallest and the largest Nash equilibria effort levels of $\Gamma_{e} \cdot{ }^{27} \mathrm{I}$ use Lemma 3 to characterize the impact of worker positive self-image on the firm's welfare when self-image and effort are complements.

Theorem 1 If $\Gamma_{e}\left(\lambda^{1}, \lambda^{2}, y_{L}, y_{W}\right)$ is a supermodular game and $H^{i}$ has increasing differences in $\left(a^{i}, \lambda^{i}\right), i=1,2$, then the firm's welfare is higher in tournament $T\left(\lambda^{1}, \lambda^{2}\right)$ than in tournament $T\left(\gamma^{1}, \gamma^{2}\right)$, with $\lambda^{i}>\gamma^{i}, i=1,2$.

Proof We know from Lemma 3 that if workers' self-image and effort are complements the smallest and the largest pure-strategy Nash equilibria of $\Gamma_{e}\left(\lambda^{1}, \lambda^{2}, y_{L}, y_{W}\right)$ are larger than the smallest and the largest pure-strategy Nash equilibria of $\Gamma_{e}\left(\gamma^{1}, \gamma^{2}, y_{L}, y_{W}\right)$. Furthermore, the workers' positive self-image relaxes the workers' participation constraints. This implies that the firm can implement the same actions with lower prizes or obtain more output for the same prizes. One way or the other the firm's welfare is higher in the tournament where workers have positive self-image than in the tournament where workers are accurate.

Q.E.D.

\footnotetext{
${ }^{26}$ To see this consider the extreme case where the distribution of the idiosyncratic shocks is degenerate, that is, the outcome of the tournament is completely deterministic. In this case, as Nalebuff and Stiglitz (1983) point out, each worker can assure that he wins the tournament by increasing his effort slightly above that of his opponent. But then, beyond some critical effort level, it is better to shirk and be certain to receive the losing prize than incurring in a very high disutility of effort and capturing the winning prize. Although there exists no pure-strategy Nash equilibrium, Nalebuff and Stiglitz (1983) show that, in their tournament model, there exists a mixed-strategy Nash equilibrium.

${ }^{27}$ Note that this result does not imply that all Nash equilibria of $\Gamma_{e}\left(\lambda^{1}, \lambda^{2}, y_{L}, y_{W}\right)$ are nondecreasing functions of $\left(\lambda^{1}, \lambda^{2}\right)$. In fact we may have that a Nash equilibrium in the interior of the set of Nash equilibria of $\Gamma_{e}\left(\lambda^{1}, \lambda^{2}, y_{L}, y_{W}\right)$ is lower than the correspondent Nash equilibrium in the interior of the set of Nash equilibria of $\Gamma_{e}\left(\beta^{1}, \beta^{2}, y_{L}, y_{W}\right)$ with $\left(\lambda^{1}, \lambda^{2}\right)$ higher than $\left(\beta^{1}, \beta^{2}\right)$.
} 


\section{Appendix 3}

This appendix shows if output is exponentially or normally distributed, then there is a non-monotonic relation between effort and self-image but the firm is still better off with a positive self-image workforce.

Proposition 5 If workers are risk averse and output is exponentially distributed, then the firm's welfare is higher in $T(\lambda)$ than in $T(1)$, with $1<\lambda<\hat{\lambda}$.

Proof Let output be exponentially distributed with mean $a^{i}$ but assume that each worker perceives it to be exponentially distributed with mean $\lambda a^{i}$, with $1<\lambda<\hat{\lambda}$. In this case we have that $P\left(Q^{i i}>q^{j}\right)=\exp \left\{-q^{j} / \lambda a^{i}\right\}$, and

$$
P\left(a^{i}, a^{j}, \lambda\right)=\frac{1}{a^{j}} \int_{0}^{+\infty} \exp ^{-\left(\frac{a^{j}}{\lambda a^{i}}+\frac{q^{j}}{a^{j}}\right)} d q^{j}=\frac{\lambda a^{i}}{a^{j}+\lambda a^{i}} .
$$

The cross partial of $P\left(a^{i}, a^{j}, \lambda\right)$ with respect to $a^{i}$ and $\lambda$ is

$$
P_{a^{i} \lambda}=\frac{a^{j}\left(a^{j}-\lambda a^{i}\right)}{\left(a^{j}+\lambda a^{i}\right)^{3}} .
$$

The sign of $P_{a^{i} \lambda}$ is positive when $a^{j} / a^{i}>\lambda$ and negative when $a^{j} / a^{i}<\lambda$. Now, let $a$ denote an arbitrary effort level that the firm can implement when workers are risk averse and have accurate self-images. The assumption of symmetry and (19) imply that $P=\lambda /(1+\lambda)$ and $P_{a^{i}}=\lambda /\left[a(1+\lambda)^{2}\right]$. Thus, the utility of the losing and winning prizes is

$$
\begin{aligned}
& u_{L}(\lambda)=\bar{U}+c(a)-(1+\lambda) a c^{\prime}(a), \\
& u_{W}(\lambda)=\bar{U}+c(a)+\frac{1+\lambda}{\lambda} a c^{\prime}(a) .
\end{aligned}
$$

The utility prize spread that implements effort level $a$ is

$$
\triangle u(\lambda)=\frac{(1+\lambda)^{2}}{\lambda} a c^{\prime}(a)
$$

If workers are accurate, then $\lambda=1$ and $u_{L}(1)=\bar{U}+c(a)-2 a c^{\prime}(a), u_{W}(1)=$ $\bar{U}+c(a)+2 a c^{\prime}(a)$, and $\triangle u(1)=4 a c^{\prime}(a)$. If workers have positive selfimage, then (20), (21) and (22) imply that the firm is able to implement 
effort level $a$ by increasing the prize spread but simultaneously reducing the winner's and the loser's prizes. This implies that $C(a, \lambda)<C(a, 1)$, for all $\lambda \in(1, \hat{\lambda})$.

Q.E.D.

Proposition 6 If workers are risk averse and output is normally distributed, then the firm's welfare is higher in $T(\lambda)$ than in $T(1)$, with $1<\lambda<\tilde{\lambda}$, where $\tilde{\lambda}=\min \left[\hat{\lambda}, .5+.5 \sqrt{\left(1+8 \sigma^{2} / a\right)}\right]$.

Proof Let output be normally distributed with mean $a^{i}$ and variance $\sigma^{2}$ but suppose that each worker perceives it to be normally distributed with mean $\lambda a^{i}$, with $1<\lambda<\tilde{\lambda}$, and variance $\sigma^{2}$. Worker $i$ 's unconditional perceived probability of winning the tournament is given by

$$
\begin{aligned}
P\left(a^{i}, a^{j}, \lambda\right) & =P\left(Q^{i i}>Q^{j}\right)=P\left(\lambda a^{i}+\varepsilon^{i}>a^{j}+\varepsilon^{j}\right) \\
& =P\left(\lambda a^{i}-a^{j}>\varepsilon^{i}-\varepsilon^{j}\right)=\Phi\left(\lambda a^{i}-a^{j}\right),
\end{aligned}
$$

where $\Phi()$ is the distribution function of a normal random variable with mean 0 and variance $2 \sigma^{2}$. The cross partial of $P\left(a^{i}, a^{j}, \lambda\right)$ with respect to $a^{i}$ and $\lambda$ is

$$
P_{a^{i} \lambda}=\frac{1}{2 \sigma \sqrt{\pi}}\left(1-\frac{\lambda a^{i}-a^{j}}{2 \sigma^{2}} \lambda a^{i}\right) \exp ^{-\frac{1}{4 \sigma^{2}}\left(\lambda a^{i}-a^{j}\right)^{2}} .
$$

We see from (23) that the sign of $P_{a^{i} \lambda}$ is positive when $2 \sigma^{2}>\left(\lambda a^{i}-a^{j}\right) \lambda a^{i}$ and negative when $2 \sigma^{2}<\left(\lambda a^{i}-a^{j}\right) \lambda a^{i} .{ }^{28}$ Now, let $a$ denote an arbitrary effort level that the firm can implement when workers are risk averse and have accurate self-images. The assumption of symmetry, (23), and $1<$ $\lambda<\tilde{\lambda}$ imply that $P_{a^{i} \lambda}>0$ at the symmetric equilibrium. It follows from Proposition 3 that the firm will reduce the mean utility prize and lower the prize spread when it wishes to implement $a$ and the workforce has positive self-image. This implies that $C(a, \lambda)<C(a, 1)$, for all $\lambda \in(\gamma, \tilde{\lambda})$. Q.E.D.

\footnotetext{
${ }^{28}$ The interpretation of these two conditions is as follows. If player $i$ thinks that player $j$ 's effort is higher than $\lambda a^{i}$ or player $i$ thinks that player $j$ 's effort is smaller than $\lambda a^{i}$ and the variance of output is high, then effort and self-image are complements. However, if player $i$ thinks that player $j$ 's effort is smaller than $\lambda a^{i}$ and the variance of output is low, then effort and self-image are substitutes.
} 


\section{References}

Ando, M. (2004). "Overconfidence in Economic Contests." Working Paper, University of Tokyo.

Athey, S., Milgrom, P., and J. Roberts (1996). Robust Comparative Statics. Unpublished Manuscript.

Baker, G., Jensen, M., and K. Murphy (1988). "Compensation and Incentives: Practice vs. Theory." Journal of Finance, Vol. XLIII, No. 3, 593616.

Brozynski, T., Menkhoff, L., and U. Schmidt (2004). "The Impact of Experience on Risk Taking, Overconfidence, and Herding of Fund Managers: Complementary Survey Evidence." University of Hannover, mimeo.

Camerer, C. (1991). "Do Markets Correct Biases in Probability Judgment? Evidence from Market Experiments," in J. Kagel and L. Green (Eds.), Advances in Behavioral Economics, 2, Northwood, NJ: Ablex Publ., 1990, 125172."

Camerer, C. and D. Lovallo (1999). "Overconfidence and Excess Entry: An Experimental Approach." American Economic Review, Vol. 89, No. 1, 306-318.

Debreu, D. (1952). "A Social Equilibrium Existence Theorem." Proceedings of the National Academy of Sciences 38, 886-893.

De la Rosa, L. (2005). "Overconfidence and Moral Hazard." University of California, Berkeley, mimeo.

Deaves, R., Luders, E. and R. Luo (2003). "An Experimental Test of the Impact of Overconfidence and Gender on Trading Activity." AFA Philadelphia Meetings, EFMA 2004 Basel Meetings Paper.

Fan, K. (1952). "Fixed Point and Minimax Theorems in Locally Convex Topological Linear Spaces." Proceedings of the National Academy of Sciences $38,121-126$.

Gervais, S. and I. Goldstein (2004). "Overconfidence and Team Coordination." Duke University mimeo.

Glicksberg, L. (1952). "A Further Generalization of the Kakutani Fixed Point Theorem with Applications to Economics." Proceedings of the $\mathrm{Na}$ tional Academy of Sciences 38, 170-174.

Grossman, J. and O. Hart (1983). "An Analysis of the Principal Agent Problem." Econometrica 51, 7-45.

Hvide, H. K. (2002). "Pragmatic Beliefs and Overconfidence," Journal of Economic Behavior and Organization, vol. 48, no. 1, 15-28. 
Koh, Winston (1992). "A Note on Modelling Tournaments." Journal of Economics, Vol. 55, No. 3, 297-308.

Kyle, A. S. and F.A. Wang (1997). "Speculation Duopoly with Agreement to Disagree: Can Overconfidence Survive the Market Test?" Journal of Finance, Vol. 52, 2073-2090.

Landier, A. and D. Thesmar (2003). "Financial Contracting with Optimistic Entrepreneurs: Theory and Evidence." Working Paper, University of Chicago Graduate School of Business.

Lazear, E. and S. Rosen (1981). "Rank-Order Tournaments as Optimum Labor Contracts." Journal of Political Economy, 89, 841-864.

Malmendier, U. and G. Tate (2002). "Who Makes Acquisitions? CEO Overconfidence and Market's Reaction." Working Paper, Harvard University.

Milgrom, P. and J. Roberts (1990). "Rationalizability, Learning, and Equilibrium in Games with Strategic Complementarities." Econometrica, Vol. 58 , No. 6, 1255-1277.

Mirrlees, J. (1975). "The Theory of Moral Hazard and Unobservable Behavior. Part I." Mimeo, Nuffield College, Oxford.

Moscarini, G. and H. Fang (2005). "Morale Hazard." Journal of Monetary Economics, Vol. 52, 749-777.

Myers, D. (1996). Social Psychology. New York: McGraw-Hill.

Nalebuff B. and J. Stiglitz (1983). "Prizes and Incentives: Towards a General Theory of Compensation and Competition." Bell Journal of Economics $14,21-43$.

Oberlechner, T. and C. Osler, 2004, Overconfidence in Currency Markets, mimeo, University of Vienna and Brandeis University.

Park, Y. and L. Santos-Pinto (2005). "Forecasts of Relative Performance in Tournaments: Evidence from the Field," Working Paper, Universidade Nova de Lisboa.

Rabin, M. (1998). "Psychology and Economics," Journal of Economic Literature, Vol. XXXVI, 11-46.

Simon, M. and S. Houghton (2003). "The Relationship between Overconfidence and the Introduction of Risky Products: Evidence from a Field Study." Academy of Management Journal, Vol. 46, No. 2, 139-149.

Squintani, F. (2006). "Equilibrium and Mistaken Self-Perception." Economic Theory, Vol. 27, No. 3, 615 - 641. 